\title{
Athletes as Tourists: Consumer Behaviour of Participants at the 2007 and 2009 World Universiade Games
}

\author{
Douglas Michele Turco ${ }^{1}$, Dimitra Papadimitrou ${ }^{2}$, \\ Serkan Berber ${ }^{3}$
}

\author{
${ }^{1}$ Drexel University, Philadelphia, USA \\ ${ }^{2}$ University of Patras, Rio, Greece \\ ${ }^{3}$ Anadalu University, Eskişehir, Turkey
}

ABSTRACT

Considerable research has been devoted to sport mega-events including the Olympic Games, the FIFA World Cup, and the Commonwealth Games. Yet few studies have focused on the lesser known or "second tier" international sport events in order to understand the patterns and the impact of participant consumption. Further, few sport event studies are extended beyond a single assessment. This study examines a recurring sport event, the World Universiade Summer Games, that took place in two different countries, Belgrade, Serbia and Bangkok, Thailand. A profile of participants at the 2007 and 2009 Universiades was generated to reveal and compare their consumer behaviour in the host cities and over time. Subjects were queried on-site during selected days of competition ( $\mathrm{N}=441,2007 ; \mathrm{N}=221,2009$ ). Findings demonstrate a remarkable consistency in participant characteristics and local spend from 2007 to 2009, though the amount spent per night was considerably less than the average per night spend by other types of tourists in the host countries, suggesting that Universiade athletes are non high-value tourists. Discussion and implications of findings to sport and tourism destination scholars and marketers are presented.

KEYWORDS $\quad$ sport tourism, mega-events, World Universiade Games

\section{Introduction}

The summer Olympic Games and the FIFA Men's World Cup are the two largest sport megaevents on the planet in terms of media audience, production costs, impact, etc.; all other events pale in comparison. Though both colossal in size they are distinct in several respects. The Olympic Games (and their impact) are more concentrated temporally and spatially than the FIFA World Cup, as the Olympics occur over 19 days and are hosted by a city (with a few satellite cites hosting a sport event). The FIFA World Cup spans 30 days and is hosted by a country with as many as nine official host cities. The Olympic Games involve world championship competitions in over 25 sports and 40 disciplines whereas the FIFA World Cup is solely football (soccer).

The competition to host the Olympic Games or a FIFA World Cup is fierce, as fierce as the athletic competition on the track, in the pool or on the pitch. Likewise, the competition is intense 
amongst cities to host other large sports events including the UEFA Euro Cup, Formula One races, IFAA World Championships, and the World Universiade. Cities and countries vie to host such events with the expectation that spending by participants, spectators, sponsors and developers will boost their economies. Businesses supplying lodging, meals, souvenirs, transport, tickets, etc., are particularly eager to accommodate sport tourists, and much is at stake: the city of Sheffield, England lost USD 18 million when it hosted the 1991 World Games (www.nytimes.com); the budget for the 2012 London Olympic Games was $£ 9.35$ billion in March 2007 and projected to be $£ 20$ billion by the time the Games begin (www.bbc.com). These sums are paltry in comparison to the USD 50 billion spent to produce the 2008 Beijing Olympic Games.

Relatively smaller sports events in smaller cities have the potential to create a relatively larger impact than the bigger events previously mentioned, particularly for smaller cities in developing countries. The direct economic impact of the 2005 Little League Baseball World Series, an international tournament for 12-13-year-old boys held annually in Williamsport, Pennsylvania, was USD 35 million, and a significant percentage of the county's (provincial) gross domestic product (GDP) for the year (Scott \& Turco 2007).

Considerable research has been devoted to sports mega-events including the Olympic Games, the FIFA World Cup, and the Commonwealth Games (Kaplanidou 2007, Preuss, Seguin \& O'Reilly 2007, Preuss 2004, Baade \& Mathieson 2002, Carlsen \&Taylor 2003), yet few studies have focused on lesser known or "second tier" international sports events in order to understand participant consumption patterns and impact (Black 2008). These events, while impressive in terms of athletic endeavor and/or number of participants, do not rise to the global popularity, investment levels or impact of the summer Olympic Games and the FIFA World Cup. Further, few sports event studies are extended beyond a single assessment. This study examines a recurring sports event, the World Universiade Summer Games, in Belgrade, Serbia and Bangkok, Thailand. A profile of participants at the 2007 and 2009 Universiades was generated to reveal and compare their consumer behaviour over time and in the host cities.

\section{World Universiade Games}

The Universiade is an international multi-sport event organized for university athletes by the International University Sports Federation (FISU). The name is a combination of the words "University" and "Olympiad." The Universiade is often referred to as the World University Games. An "International Universities Championship" was held in 1923 under the auspices of the Union Nationale des Étudiants Français (UNEF). The official "Summer Student World Championships" were organised by the Confédération Internationale des Étudiants (CIE) from 1924 and were renamed the "International University Games" in 1930. From 1949 onwards a biennial "Summer International University Sports Week" was organised by the Fédération Internationale du Sport Universitaire (FISU) and became the "World University Games" in 1957. The first event officially titled "Universiade" began in 1959. Shenzhen, China will host the 2011 Summer Universiade and Kazan, Russia and Gwangju, Korea will host the 2013 and 2015 Summer Universiades, respectively.

The World Universiade is one of the world's largest sporting events, yet remains relatively obscure due to limited media attention. In 2009, 8,600 athletes from 145 countries participated in the $25^{\text {th }}$ World Universiade in Belgrade, Serbia. The $24^{\text {th }}$ World Universiade was held in Bangkok from 818 August 2007 and set a new standard with 9,006 participants from 152 countries. Over 6,000 athletes competed in 18 sports. Universiade participants in Bangkok had access to 43 sites for practice and 36 sites for competitive events. Athletics was the most popular sport, with 779 men and 550 women from 118 countries participating. 


\section{Review of literature}

Few research studies have examined visitors to recurring sport mega-events over time. Termed hallmark events by Ritchie (1984), these large-scale contrivances are distinguished from other occurrences as:

Major one-time or recurring events of limited duration, developed primarily to enhance the awareness, appeal and profitability of a tourism destination in the short and/or long term. Such events rely for their success on uniqueness, status, or timely significance to create interest and attract attention.

Following the 2003 Cricket World Cup in South Africa, Zimbabwe and Kenya, Turco and Ally (2008) studied spectators at the 2007 Cricket World Cup matches in Guyana. They found that visitors from the United States accounted for $50 \%$ of the total spectator sample; those from Caribbean countries formed $25 \%$, followed by Canada with $13 \%$. While the U.S. is not known as a cricketplaying nation, many of the visitors from the U.S. were of Guyanese heritage and returned to their place of ancestry because of the Cricket World Cup (CWC). The authors later compared visitor spending at the 2003 and 2007 CWCs. Visitors to South Africa spent an average of ZAR 1,400 per day (approximately USD 190) for an average of 16 days. Per day visitor spending figures for the 2003 and 2007 CWCs were nearly identical (USD 190 for 2003 and USD 191 in 2007). The 2003 CWC matches in South Africa were attended by 626,845 people, while the 2007 CWC sold more than 672,000 tickets and recorded the highest ticketing revenue for a CWC. The average length of stay of a foreign visitor during the 2003 CWC was 16 days, which was slightly longer than for the average non-CWC foreign visitor (12 days).

There seems to be a World Cup for almost every sport, including Federation football, cricket, alpine skiing, and ice climbing. The Ice Climbing World Cup finals were held 5-8 February 2009 in the small Romanian town of Busteni, Romania. Busteni is situated in the center of Romania in the Bucegi Mountains, and sits at an altitude of $900 \mathrm{~m}$. Busteni has approximately 19,000 residents, though the total number of inhabitants varies due to tourism seasonality. Busteni is located 131 kilometers north of Bucharest and $35 \mathrm{~km}$ south of Brasov. Prior to the 2009 finals in Busteni, three other World Cup competitions were held: Daone, Italy (16-18 January), Saas Fee, Switzerland (22-24 January), and Mostrajna, Slovenia (31 January). Participant profiles in Busteni were complied by Turco, Dinu, and Goicea (2009) from data obtained through surveys of 45 of the 52 competitors. In-depth interviews with the participants took place in the isolation room prior to the lead climb competition. A second survey was conducted two weeks after the competition to determine when participants began climbing, prior sport participation, social benefits of climbing, self-identification as a serious climber, travel behaviours, etc. Competitors stayed an average of 4.5 days in Busteni for the World Cup Ice Climbing finals. Their average spend in Busteni was $€ 69.02$ for lodging, $€ 53.54$ shopping, $€ 72.50$ for eating and drinking, $€ 28.18$ for entertainment, and $€ 91.82$ for other goods and services for a total average spend of $€ 315.06$. In aggregate, climbers spent an estimated $€ 16,383$ in Busteni, where the spend per day averaged $€ 70.01$. Eighty-four percent of the respondents had competed in the World Cup before the 2009 event in Busteni; 68.9\% had previously visited Romania. Forty-two percent of the subjects had family and/or close friends travel to Busteni to watch them compete. Most competitors in the 2009 Ice Climbing World Cup began climbing when they were in their late teens to early twenties after having participated in other sports e.g. football, gymnastics, and equestrian. They found climbing more physically challenging and rewarding than the other sports. Many were socialized into climbing by their parents at a young age, and now have spouses and dependents that also climb. The authors concluded that competitive ice climbers are not high-end sports tourists in part because of the nature of the sport. Ice climbers are conditioned to no- or low-cost accommodations, typically sleeping in tents, sleeping bags, mountain cabanas or low-cost hotels, dormitories or hostels. On some training climbs they will sleep on the mountain in special hammocks. They do not indulge on expensive cuisine. Their economic impact on the host community is therefore minimal. World Cup ice climbing competitors, though not significant spenders, serve an important role in the sport tourism system, attracting 
spectators (and their spending) to the destination; these are visitors who would not otherwise visit. In this regard, competitions involved in "fringe" sports can be valuable assets worthy of investment for a host community.

Since 11 September 2001, terrorism and security concerns have been heightened at large scale sport events. At the 2008 Beijing Olympic Games, spectators were required to go through no less than three security screening checkpoints before entering a competition venue. Spectator handbags were carefully checked and hundreds of uniformed soldiers were placed near entrances/exits. In a study of 277 attendees at the 2004 Athens Olympics, Taylor and Toohey (2007) found that those who reported being fearful or feeling unsafe at the Games displayed increased risk estimates and associated concerns, whilst respondents expressing defiance and anger produced opposite reactions. Additionally, men were more likely than women to report that increased security measures detracted from their experience at the Olympic Games.

Starting in the $1980 \mathrm{~s}$, hosting sport mega-events became an urban economic regeneration strategy, supplanting more social motivations i.e., youth sport development, improved public health, enhanced quality of life, etc. (Carlsen \& Taylor 2003, Jones \& Stokes 2003, Lynch \& Jensen 1984). The purpose of staging sport events shifted from entertainment for locals to attracting tourists and encouraging their local spend. Writes Gratton, Shilbi, and Coleman (2005, p. 985):

\section{Investment in sport infrastructure in cities was not primarily aimed at getting the local community involved in sport, but was instead aimed at attracting tourists, encouraging inward investment and changing the image of the city. The first example of this new strategy was seen in Sheffield with the investment of £147 million in sporting facilities to host the World Student Games of 1991.}

The authors note that Sheffield, Birmingham and Glasgow used sports as a key driver in promoting urban regeneration. Each city was designated as a National City of Sport in 1995.

Similarly, Manchester, England, spent over $£ 200$ million on sports facilities to host the 2002 Commonwealth Games, with an additional $£ 470$ million spent on non-sport infrastructure in east Manchester. Manchester's transformation from a working-class port city to international sport tourism destination was initiated by hosting the Commonwealth Games. It is an understatement that the popularity of Manchester United has significantly aided the city's sport and tourism image.

Urban regeneration through sport events, Smith (2005) claims, leads to a reimaging of the city. Nowhere has this been more renown than Barcelona, Spain, host of the 1992 Olympic Games. The European Cities Monitor ranks the top cities in which to locate a business on the continent. In 1990, Barcelona was ranked eleventh; in 2007, it ranked fourth, ahead of Amsterdam, Brussels, and Madrid. The Olympic Games in Barcelona generated an estimated USD 16.6 billion for the national economy between 1986-1993 (Visit Britain 2004). Tourism accounts for over 12\% of the city's GDP, compared to $1-2 \%$ before the Olympics (Cabrini 2004).

Barcelona increased its capacity of hotel beds by $34.9 \%$ in the buildup to the Olympics and continued to do so following the Games. Between 1992-2002, 75 additional hotels were built, resulting in a $47 \%$ expansion of available bed space (Duran 2002). Overnight stays rose by $110 \%$ between 1990 and 2001, outperforming the 98\% increase in beds during that period. Concerning the image makeover Barcelona experienced from the Olympic Games, Pere Duran, the general director of the Tourisme de Barcelona Consortium, stated: "Barcelona was a grey and boring city. The Games were the excuse, perhaps the incentive, for a general process of analysis of the city in general and in particular its role as a tourist centre" $(2002,7)$. Examining the Studying the impact of destination image on event image, Xing and Chalip (2006) found a transfer of image between destinations and events, implying that the impact of destination image on event image could be considerable. For successful destination branding, marketers need to better understand how destination images impact the image of the events they are hosting (Kaplanidou and Vogt 2007). Some destinations are inextricably linked to the sport events they host. Consider Indianapolis and the Indy 500 motor race, 
Pamplona and the Running of the Bulls, and Augusta, Georgia and the Masters Golf Championship. Co-branding destinations and events requires a mutually positive interrelationship between event and destination images.

Previous research on relatively large-scale, second-tier sport events including the Commonwealth Games, World Universiade, and America's Cup, have focused on visitor spend, security, urban regeneration, and reimaging the host city. Tourists, residents, and local businesses were queried. What is missing is the perspective of event participants, and there may be several explanations why.

Athletes are not included in some sport tourism studies for a number of reasons. First, in economic impact studies, athletes often stay in lodging accommodations that are complimentary or paid for by their national sport federations, and provided with cafeteria-style meal services; consequently, their local spend is therefore much less than other tourists. Second, researchers may find it difficult to access athletes because of their competition and practice schedules. Third, event organizers may not want athletes to be distracted from their competition focus by researchers asking invasive questions.

\section{Research methods}

A questionnaire modeled after the one used by Cox et al (2007) was developed to facilitate the purpose of the study. For the 2007 Bangkok Universiade study, a total of 441 on-site participant surveys were completed during selected days of the event (Papadimitrou and Turco 2009). Likewise, a survey of participants at the 2009 Belgrade World Universiade was performed to ascertain their trip characteristics, socio-demographic profiles, and consumer behaviour. A total of 221 participant interviews were completed at selected competition venues. A comparison of participant responses to the surveys at the 2007 Bangkok and 2009 Belgrade Universiades was performed with the following results.

\section{Results and discussion}

Table 1 offers a side-by-side comparison of World Universiade Games participant characteristics for the 2007 and 2009 editions. Participants in 2007 and 2009 were statistically similar with respect to age (27.5 years in 2007; 26.81 years in 2009), gender (approximately $60 \%$ male and $40 \%$ female), and length of stay ( $2007=12$ nights; $2009=13$ nights). It was expected that a higher proportion of participants would be Asian for the 2007 Bangkok Universiade Games than for 2009, and this was confirmed. Whites represented $66 \%$ of the participants in $2007,11.5 \%$ were Asian, $11 \%$ Black, 6\% Latina/Latino, and 3\% Indian. In the 2009 Belgrade Games, the overwhelming majority of participants were White (82.4\%), while Black (7.2\%), Latino/Latina (6.3\%) and Asian (1.4\%) participants were represented in much smaller numbers. They were accompanied by an average of 2.2 relatives/friends.

Participant spending in 2007 and 2009, once adjusted for inflation, was remarkably consistent. On average, participants spent $€ 801.33$ in Bangkok and $€ 815.60$ in Belgrade during the Universiade World Games, respectively, primarily for event tickets, shopping, transportation, and other goods and services. There may be only so much time, shopping access, and money available to Universiade participants, regardless of where they are, and $€ 800$ appears to be their spending threshold. Per night spend by participants averaged $€ 67$ in 2007 and $€ 63$ in 2009, not exactly the spend of high-end tourists. It must be remembered that most of the participants are students (or recent college graduates) and amateur athletes. They may not have been employed at the time or had previous opportunity to acquire a high-paying job thus having a negative impact on their tourist spend. By comparison, the average foreign tourist in Thailand stayed 7.93 nights and spent USD 84 per day (Pongsirirushakun and Naewmalee 2003). In Serbia, the average international tourist in 2009 stayed 2.28 nights. 
According to the National Bank of Serbia (www.nbs.rs), the average per day per capita spend by foreign tourists in Serbia is approximately $€ 350$, with averages varying by country of origin. For example, tourists from Belgium spend $€ 2,228$ in Serbia; United Kingdom $€ 1,741$; Germany $€ 1,922$; USA $€ 597$; Switzerland $€ 133$; Austria $€ 68$; France $€ 64$; Russia $€ 36$; Slovenia $€ 33$; and Croatia $€ 25$.

Table 1. Comparison of 2007 and 2009 World Universiade participants by selected characteristics

\begin{tabular}{lcc}
\hline Variable & 2007 Bangkok & 2009 Belgrade \\
\hline Length of stay & 12 nights & 13 nights \\
Gender & $60 \%$ male & $62 \%$ male \\
& $40 \%$ female & $38 \%$ female \\
Age & 27.5 years & 26.81 years \\
Total spend & $€ 801.33$ & $€ 815.60$ \\
First time participants & $63.0 \%$ & $66.1 \%$ \\
Return visit to host city? & Yes $-51.0 \%$ & Yes $-49.8 \%$ \\
Race & No - $9.0 \%$ & No - 5.9\% \\
$-\quad$ Asian & & \\
$-\quad$ White & $11.5 \%$ & $1.4 \%$ \\
$-\quad$ Latino & $66.0 \%$ & $82.4 \%$ \\
$-\quad$ Black & $6.0 \%$ & $6.3 \%$ \\
$-\quad$ Indian & $11.0 \%$ & $7.2 \%$ \\
- Other & $3.0 \%$ & $0.5 \%$ \\
\hline
\end{tabular}

In terms of willingness to return to the host city, a slightly higher percentage of the 2007 participants expressed interest in returning to Bangkok than the 2009 participants to Belgrade. In 2007, $51 \%$ of participants indicated that they would visit Bangkok in the future, $39.8 \%$ were not sure, and $9 \%$ would not visit again. Approximately $87 \%$ of participants would recommend visiting Bangkok to their friends, and $13 \%$ would not. In 2009 , less than half the subjects $(49.8 \%)$ indicated that they would return to Belgrade as visitors, $5.9 \%$ would not return and $44.3 \%$ were not sure.

This study reveals the market characteristics and consumer behaviour of participants at an international sport event held in two different countries held two years apart. Results show consistency in travel and spending but slight differences in race and willingness to recommend visiting the destination to others. It is recommended that researchers replicate studies of recurring sport events held in different host countries to determine the similarities and differences in sport participant characteristics and impact across time and cultures.

One of the most vexing questions for sports event and destination marketers is "How much does the average sports event tourist spend per trip?" The answer depends on the nature of the sports event, spectator market, and characteristics of the host economy. The spatial proximity/distance of sport tourists in relation to the host economy, and whether or not they are first-time visitors, influences their spending. Event visitors from communities nearer the host economy typically spend fewer dollars than those from greater distances. International visitor groups to the 2005 Little League World Series spent, on average, USD 700 more in the Williamsport economy than domestic visitor groups (Scott and Turco 2007). The implications can be important to tourist destination marketers. As the geographic origins of event spectators changes from year to year, so too will their economic impact on the host economy. For the Universiade World Games, it appears that the average participant spend is approximately $€ 800$ in the local economy. The costs for an athlete's lodging and some meals are typically paid for by their national sport federations and therefore their personal spend locally will be less than other sport tourists. Given the nature of the Universiade, with practices and preliminary competitions in some events, an athlete may not have the time to spend additional money in the host city. More directly, student athletes may simply not yet have the spending power (income) to add more money to the local economy.

Though the focus of this research has been on the World Universiade, it must be remembered that different sports events stimulate different spectator spending behaviour. For example, youth 
sporting events may benefit an economy more than those for university athletes, since the youth are often accompanied by parents/guardians, thereby attracting a larger visitor group. Friends of student athletes may likely be students and therefore in similar financial circumstances: little disposable income available to travel to a Universiade and watch their friends. This study examined Summer Universiade participants. Winter Universiade participants may or may not spend at different levels and therefore should be studied in the future.

The prestige of an event as perceived by sport consumers also influences the size of the visitor group and their spending. Turco (2000) found that playing in a state high school championship is literally and figuratively a "once-in-a-lifetime" opportunity for most participants. Once a person graduates from high school they obviously cannot compete in such a championship again. The clock is ticking and there is a sense of urgency and scarcity for the participant and spectator. State high school sport championships attract large numbers of spectators who are relatives/friends of the athletes. The same can be said for college student athletes. The World Universiade is an important event in the lives of its participants, but for many U.S. athletes, the Universiade neither holds the international prominence nor attracts the media coverage of a National Collegiate Athletic Association (NCAA) championship in the U.S.

First-time event visitors often spend considerably more than repeat visitors who have "been there, done that," and may not feel the need to do "that" again (whatever that may be). Tang and Turco (2001) showed that repeat visitor groups to a sport event, the Albuquerque International Balloon Fiesta, spent USD 189.56 less than first-time visitors. The nature of the World Universiade is such that few participants can compete again. Most are likely to complete their schooling and are thus ineligible for future Universiades, and/or have moved on to higher-level competitions, or ended their athletic pursuits for career employment opportunities. Event participants may return to the destination as leisure tourists someday. This is especially desirable for Serbia, as tourism volume and tourism receipts dropped dramatically last decade due to domestic and international factors not related to tourism. Total tourism volume fell by $47.9 \%$, foreign tourism declined $82.9 \%$, and receipts from international tourism dropped 93.6\% (Statistical Office of the Republic of Serbia: webrzs.stat.gov.rs).

Some recurring events seem to attract high-end consumer groups (i.e., America's Cup yacht race, Masters Golf Tournament, Virginia Gold Cup Steeplechase, etc.), while other events attract more thrifty visitors. Consider the high-end sponsors of the $32^{\text {nd }}$ America's Cup - Louis Vuitton, Oracle, and BMW. One would surmise that visitor spending would be higher among spectators and participants who attend up-scale events per day/per capita, generating significant economic benefits. However, certain events not noted for attracting affluent markets may lure large numbers of visitors and have a considerable net impact on a local economy if the sport event lasts longer. Future research should examine the extent to which repeat visitation, perceived event prestige, and age of participant influence sport event tourist attendance and spending behaviour. For example, Kaplanidou and Vogt (2007) recommend examining the perceptions of event and destination images that elite sport tourists hold, and the ways these images impact their athletic performances and intention to revisit the destination. In addition, the extent to which the tourist images of Bangkok and Belgrade have been influenced by hosting the World Universiade should be examined more closely. Universiade participants expressed a willingness to recommend visiting the cities to their friends and relatives. Both cities are known for their cultural and historical attractions and not for hosting premier sporting events. Neither is an applicant city for an Olympic Games for 2020. Reimaging a city is a process that cannot be completed overnight or in a few weeks time. Olympic cities have the benefit of years of planning and preparation, three weeks of competition, intense worldwide media coverage, and a postGames legacy that may last for years. These elements are absent, or are considerably less intense, in the case of the World Universiade or other second-tier sport events. 


\section{REFERENCES}

Baade, R. A., Matheson, R. A. (2002). Bidding for the Olympics: fool's gold? In C. P. Barros, M. Ibrahim and S. Szymanski (Eds.), Transatlantic sport: The comparative economics of North American and European sports (pp. 127-151). Cheltenham, UK: Edward Elgar.

Black, D. (2008). Dreaming big: The pursuit of 'second order' games as a strategic response to globalization. Sport in Society, 11(4), 467-481.

Cabrini, L. (2004). http://www.worldtourism.org/regional/europe/PDF/SPEECHES/2004/Austria16-19June 2004.pdf.

Carlsen, J., Taylor, A. (2003). Mega-events and urban renewal: The case of the Manchester 2002 Commonwealth Games. Event Management, 8(1), 15-22.

Cox, M. F., Turco, D. M., Ally, S. A., McAlmont, C., Sukhdeo-Singh, T. (2007). 2007 Cricket World Cup Super Eight Series Spectator Profile - Final Report. Georgetown: University of Guyana.

Duran, P. (2002). http://olympicstudies.uab.es/eng/obs_det.asp?id_recurs=104.

Gratton, C., Shibli, S., Coleman, R. (2005). Sport and economic regeneration in cities. Urban Studies, 42 (5/6), 985-999.

Jones, M., Stokes, T. (2003). The Commonwealth Games and urban regeneration: an investigation into training initiatives and partnerships and their effects on disadvantaged groups in East Manchester. Managing Leisure, 8(4), 198-211.

Kaplanidou, K. (2007). Affective event and destination image: Their influence on Olympic travelers' behavioral intentions. Event Management, 10, 2, 159-173.

Kaplanidou, K., Vogt, C. (2007). The interrelationship between sport event and destination image and sport tourists' behaviours. Journal of Sport and Tourism, 12, 3-4, 183-206.

Lynch, P. G., Jensen, R. C. (1984). The economic impact of the XII Commonwealth Games on the Brisbane region. Urban Policy and Research, 2(3), 11-14.

Papadimitrou, D., Turco, D. M. (2009). The significance of the 2007 Universiade to the economy of Bangkok: Estimating sport tourist consumption. Universiade Belgrade 2009 FISU Conference, 3 July 2009, Belgrade, Serbia.

Pongsirirushakun, A., Naewmalee, K. (2003). An analysis of foreign tourist expenditure in Thailand, TDRI Quarterly Review, 18, 2, 9-16.

Preuss, H., Seguin, B., and O'Reilly, N. (2007). Profiling major sport event visitors: The 2002 Commonwealth Games. Journal of Sport \& Tourism, 12(1), 5-23.

Preuss, H. (2004). Economics of staging the Olympic Games: A comparison of the Games 1972-2008. Cheltenham: Edward Elgar.

Ritchie, J. B. R. (1984). Assessing the impacts of hallmark events: Conceptual and research issues. Journal of Travel Research, 23(1), 2-11.

Scott, A. K. S., Turco, D. M. (2007). VFRs as a segment of the sport event tourist market. Journal of Sport and Tourism, 12(1), 41-52.

Smith, A. (2005). Reimaging the city: the value of sport initiatives. Annals of Tourism Research, 32(1), $217-$ 236.

Tang, Q., Turco, D. M. (2001). A profile of high-value event tourists. Journal of Convention and Exhibition Management, 3(2), 33-40.

Taylor, T., Toohey, K. (2007). Perceptions of terrorism threats at the 2004 Olympic Games: Implications for sport events. Journal of Sport \& Tourism, 12(2), 99-114.

Turco, D. (2000). Dimensions of sport tourism. Presentation at Sport in the City: An International Conference, June 28 - July 1, 2000, Indianapolis, Indiana.

Turco, D. M., Dinu, M, Goicea, A. (2009). What's up at the 2009 Ice Climbing World Cup? Presented at the European Association for Sport Management Conference, 18 September 2009, Amsterdam.

Xing, X., Chalip, L. (2006). Effects of hosting a sport event on destination brand: a test of co-branding and match-up models. Sport Management Review, 9, 49-78.

\section{AUTHOR'S ADDRESS: Douglas Michele Turco}

International Sport Tourism Research co-Laboratory, Drexel University

One Drexel Plaza, 3001 Market St., Suite 100

Philadelphia, PA 19104 USA

Email: douglasmicheleturco@gmail.com 